\title{
PENGEMBANGAN SISTEM INFORMASI PENDAPATAN DEALER MOTOR BERBASIS OBJECT ORIENTED
}

\author{
Noerlina ${ }^{1}$ \\ ${ }^{1}$ Jurusan Komputerisasi Akuntansi, Fakultas Ilmu Komputer, Universitas Bina Nusantara, \\ Jl. K.H. Syahdan No. 9, Kemanggisan/Palmerah, Jakarta Barat 11480, \\ nurlina@binus.edu
}

\begin{abstract}
Article explores income system must be design to make easy on the company business process, able to monitor, and well operation control. Research used analysis and designed method. The analysis result later used to design a new information system that hoped able to support the company operational activity also solving problem that occurred from the running system, and able to support the company management in receiving the fast and accurate information also to give report to help the manager in making decision.
\end{abstract}

Keywords: information system, income, object oriented

\begin{abstract}
ABSTRAK
Artikel menjelaskan sistem pendapatan yang harus dirancang untuk mempermudah jalannya proses bisnis perusahaan, dapat dimonitor, dan terkendali dengan baik. Metode yang digunakan adalah metode analisis dan perancangan. Kemudian digunakan untuk merancang sistem informasi baru yang diharapkan dapat mendukung aktivitas operasional perusahaan serta mengatasi masalah yang timbul dari sistem yang berjalan, dan dapat mendukung pihak manajemen perusahaan dalam memperoleh informasi yang diperlukan dengan cepat dan akurat serta penyajian laporan untuk membantu manajer dalam pengambilan keputusan.
\end{abstract}

Kata kunci: sistem informasi, pendapatan, object oriented

\section{PENDAHULUAN}

Dengan semakin ketatnya persaingan, perusahaan yang bergerak dalam bidang dealer kendaraan bermotor memandang perlu untuk menerapkan sistem informasi pendapatan yang terkomputerisasi agar lebih mempermudah pengelolaan transaksi dan kegiatan bisnis serta kemudahan dalam monitoring dan pengambilan keputusan. Untuk membantu perusahaan, telah dilakukan penelitian yang menganalisis dan merancang sistem yang dapat memenuhi kebutuhan tersebut.

Tujuan yang ingin dicapai dalam penelitian ini adalah setelah sistem diimplementasikan, akan mempermudah perusahaan dalam me-review kegiatan perolehan pendapatan perusahaan. Manfaat yang dapat diperoleh adalah meningkatkan kinerja usaha, membantu manajemen dalam melihat laporan terkait, serta penyajian laporan dengan lebih cepat, tepat, dan akurat.

Lingkup tahapan penelitian terdiri dari analisis sistem yang berjalan dan perancangan aplikasi. Analisis sistem yang berjalan difokuskan pada sistem pendapatan yang terdiri dari penerimaan pesanan, pengecekan persediaan pesanan, pemilihan status pembayaran, penerimaan pembayaran tunai dari pelanggan, permintaan persetujuan leasing dalam penjualan kredit, pengiriman barang, serta penerimaan pembayaran dari leasing dalam penjualan kredit. Perancangan aplikasi dilakukan terhadap sistem pendapatan dengan basis objek (object-oriented). 


\section{PEMBAHASAN}

\section{Sistem Pendapatan}

Secara umum, sistem pendapatan merupakan serangkaian prosedur yang dilaksanakan bersama-sama dengan tujuan untuk menghasilkan pendapatan bagi perusahaan. Sistem pendapatan biasanya terdiri dari kegiatan penjualan dan penerimaan kas. Menurut Standar Akuntansi Keuangan (1999, PSAK No. 23.2), penjualan adalah arus masuk bruto dari manfaat ekonomi yang timbul dari aktivitas normal perusahaan selama suatu periode, bila arus masuk mengakibatkan kenaikan ekuitas yang tidak berasal dari kontribusi penanaman modal. Menurut Mulyadi (2001:455), penerimaan kas dapat berasal dari dua sumber utama, yaitu penerimaan kas dari penjualan tunai dan penerimaan kas dari piutang dagang. Sumber penerimaan kas terbesar suatu perusahaan dagang berasal dari transaksi penjualan tunai.

\section{Unsur dan Tujuan Pengendalian Intern}

Menurut Mulyadi (2001:164), unsur pokok dari sistem pengendalian intern adalah struktur organisasi yang memisahkan tanggung jawab fungsional secara tegas, sistem wewenang, dan prosedur pencatatan yang memberikan perlindungan yang cukup terhadap kekayaan, utang, pendapatan dan biaya, praktik yang sehat dalam melaksanakan tugas dan fungsi setiap unit organisasi, dan karyawan yang mutunya sesuai dengan tanggung jawabnya.

Menurut Mulyadi (2001:163-164), tujuan pokok sistem pengendalian intern dapat dibedakan menjadi dua, yaitu pengendalian intern akuntansi dan pengendalian intern administratif. Pengendalian intern akuntansi merupakan bagian dari sistem pengendalian intern yang meliputi struktur organisasi, metode, dan ukuran yang dikoordinasikan, terutama untuk menjaga kekayaan organisasi dan mengecek ketelitian dan keandalan data akuntansi. Pengendalian intern administratif meliputi struktur organisasi, metode, dan ukuran yang dikoordinasikan, terutama untuk mendorong efisiensi dan dipatuhinya kebijakan manajemen.

\section{Tahapan Pengembangan Sistem Berbasis Objek}

Menurut Jones dan Rama (2003), pengembangan sistem berbasis objek melalui tahapan pembuatan activity diagram, workflow table, UML class diagram, dan use case. Activity diagram adalah diagram yang menunjukkan urutan aktivitas dalam suatu proses. Workflow table adalah suatu tabel dua kolom yang mengidentifikasi aktor dan aktivitas dalam suatu proses. Aktor yang melakukan aktivitas yang spesifik ditulis pada kolom sebelah kiri sedangkan aktivitas yang berkaitan ditulis disebelah kanan.

UML class diagram adalah diagram yang dapat digunakan untuk mendokumentasikan tabel dalam sistem informasi, hubungan antar tabel, dan sifat pada tabel. Use case adalah sebuah urutan dari langkah yang melibatkan interaksi antara aktor dengan sistem untuk tujuan utama.

\section{Proses Bisnis dan Masalah yang dihadapi}

Activity Diagram pada Gambar 1, Gambar 2, dan Gambar 3 memberikan gambaran bagaimana proses bisnis selama dijalankan di perusahaan.

Menurut hasil analisis, terlihat bahwa permasalahan yang dihadapi oleh perusahaan adalah pengolahan transaksi penjualan yang sangat lambat sehingga mengakibatkan ketidakpuasan pelanggan maupun manajemen; Laporan yang dibutuhkan oleh pihak manajemen sering mengalami keterlambatan dan sering terjadi kesalahan perhitungan dalam laporan tersebut; Tidak terdapat perincian harga yang harus dibayar oleh pelanggan pada surat pesanan; Pada penjualan tunai, tidak terdapat bukti pembayaran untuk pelanggan.

\section{Usulan Pemecahan Masalah}

Melihat gambaran umum permasalahan yang dihadapi oleh perusahaan, sangat dibutuhkan suatu sistem informasi pendapatan yang dapat membantu dalam pengolahan data dan penyajian laporan pendapatan. Penerapan Sistem Informasi Pendapatan secara terkomputerisasi akan mempercepat pengolahan data dan mempermudah pengendalian pendapatan perusahaan sehingga semua informasi dapat dihasilkan dengan cepat, tepat, dan akurat. 
Gambar 1 Overview Activity Diagram (Penjualan Tunai) 
Gambar 2 Overview Activity Diagram (Penjualan Kredit) 
Gambar 3 Overview Activity Diagram (Penerimaan Kas) 


\section{Pembahasan}

Untuk mengatasi permasalahan tersebut, dirancang sebuah sistem informasi yang memenuhi kebutuhan yang ada serta pengendalian internal tetap terjaga dengan baik. Pemisahan fungsi yang ada juga dijaga sedemikian rupa sehinggga kesalahan atau kecurangan dapat diminimalisasi.

\section{Prosedur Penjualan Tunai yang Diusulkan}

Ketika pelanggan datang ke dealer dan telah menetapkan pilihan warna dan tipe sepeda motor yang diinginkan maka akan melakukan negosiasi harga dengan sales counter. Jika sudah sepakat maka pelanggan melakukan pemesanan barang dan sales counter akan meminta persyaratan sebagai berikut. Pertama, bagi perusahaan: copy SIUP, domisili, surat pengurusan BBN di atas kop surat asli, materai + stempel + tanda tangan, Form Permohonan BPKB (stempel + tanda tangan). Kedua, perorangan: copy KTP.

Setelah persyaratan dilengkapi oleh pelanggan maka sales counter meng-entry pesanan pada form Surat Pesanan. Sales counter akan mengecek terlebih dahulu. Jika pelanggan yang memesan adalah pelanggan baru maka sales counter terlebih dahulu memasukkan data lengkap dari pelanggan baru tersebut ke dalam ms_pelanggan. Sales counter akan mencetak SP (Surat Pesanan) sebanyak 3 rangkap:

$$
\begin{aligned}
& \text { Rangkap } 1 \text { : Pelanggan } \\
& \text { Rangkap } 2 \text { : Administrasi } \\
& \text { Rangkap } 3 \text { : Accounting }
\end{aligned}
$$

Selanjutnya, sales counter memberikan SP untuk ditandatangani dan Faktur STNK/BPKB yang sudah disediakan untuk dapat diisi nama beserta alamat oleh pelanggan sebanyak 4 rangkap:

Rangkap 1 : Biro Jasa -untuk STNK-

Rangkap 2 : Biro Jasa -untuk BPKB-

Rangkap 3 : Administrasi

Rangkap 4 : Pelanggan

Setelah SP ditandatangani dan Faktur STNK/ BPKB diisi oleh pelanggan maka diberikan kepada sales counter yang kemudian diserahkan ke Administrasi. Pelanggan melakukan pembayaran tunai ke Kasir atau transfer ke rekening dealer. Kasir akan meng-entry pembayaran yang sudah dilakukan pelanggan ke form pembayaran dan mencetak Kwitansi sebanyak 3 rangkap:

$$
\begin{aligned}
& \text { Rangkap } 1 \text { : Pelanggan } \\
& \text { Rangkap } 2 \text { : Accounting } \\
& \text { Rangkap } 3 \text { : Kasir }
\end{aligned}
$$

Setelah Administrasi menerima Faktur STNK/BPKB dari sales counter maka akan menyerahkan Faktur STNK/BPKB ke biro jasa untuk dapat diurus pembuatan STNK dan BPKB. Selanjutnya, Administrasi meng-entry form Faktur Penjualan dan form Surat Jalan. Administrasi akan mencetak FP (Faktur Penjualan) sebanyak 4 rangkap: Rangkap 1 : Pelanggan Rangkap 2: Administrasi Rangkap 3 : Sales Counter Rangkap 4 : Kasir

Dan mencetak SJ (Surat Jalan) sebanyak 4 rangkap:

$$
\begin{aligned}
& \text { Rangkap } 1 \text { : Delivery } \\
& \text { Rangkap } 2 \text { : Pelanggan } \\
& \text { Rangkap } 3 \text { : Administrasi } \\
& \text { Rangkap } 4: \text { Kasir }
\end{aligned}
$$

Setelah FP dan SJ dicetak maka SJ akan diserahkan ke PDI dan FP ke Delivery kemudian PDI menyiapkan sepeda motor yang dipesan. Lalu menyerahkan barang beserta SJ ke Delivery dan Delivery akan mengirim barang beserta FP dan SJ ke pelanggan. Kemudian setelah menerima barang yang dipesan, pelanggan akan menandatangani SJ tersebut dan Delivery memberikan SJ rangkap 2 dan FP rangkap 1 ke pelanggan. Lalu Delivery menerima SJ sisanya.

Setelah Biro Jasa selesai mengurus STNK dan BPKB kemudian menyerahkan STNK dan BPKB yang sudah jadi ke Sales Counter. Sales Counter kemudian akan menghubungi pelanggan untuk dapat mengambil STNK dan BPKB ke dealer.

\section{Prosedur Penjualan Kredit yang Diusulkan}

Ketika pelanggan datang ke dealer dan telah menetapkan tipe dan warna sepeda motor yang diinginkan kemudian Sales Counter mengajukan persyaratan kredit yang harus dipenuhi oleh pelanggan, sebagai berikut. Pertama, perusahaan: copy KTP pengurus, anggaran dasar, SIUP, NPWP, TDP, rekening selama 3 bulan terakhir. Kedua, 
perorangan: copy KTP suami/istri/penjamin, KK, rekening listrik, PBB, slip gaji/ rekening tabungan.

Setelah pelanggan melengkapi persyaratan kemudian pelanggan memilih leasing yang akan digunakan. Sales counter akan mengecek terlebih dahulu, jika pelanggan yang memesan adalah pelanggan baru maka sales counter terlebih dahulu memasukkan data lengkap dari pelanggan baru tersebut ke dalam ms_pelanggan. Sales Counter akan menghubungi pihak leasing dengan memberikan data pelanggan untuk dilakukan survey terhadap pelanggan. Sales Counter meng-entry pesanan ke form Surat Pesanan dan mencetak Surat Pesanan (SP) sebanyak 3 rangkap:

\section{Rangkap 1 : Pelanggan \\ Rangkap 2 : Administrasi \\ Rangkap 3 : Accounting}

Sales counter akan memberikan SP untuk ditandatangani dan Faktur STNK/BPKB yang sudah disediakan oleh AHM (Astra Honda Motor) untuk dapat diisi nama beserta alamat oleh pelanggan sebanyak 4 rangkap:

Rangkap 1 : Biro Jasa -untuk STNK-

Rangkap 2 : Biro Jasa -untuk BPKB-

Rangkap 3 : Administrasi

Rangkap 4 : Pelanggan

Setelah SP ditandatangani dan Faktur STNK/ BPKB diisi oleh pelanggan maka akan diberikan kepada sales counter yang kemudian akan diserahkan ke Administrasi. Pada saat yang bersamaan, pelanggan akan melakukan pembayaran DP (uang muka) ke Kasir lalu Kasir meng-entry pembayaran ke form pembayaran dan kasir akan mencetak Kwitansi sebanyak 3 rangkap:

\section{Rangkap 1 : Pelanggan \\ Rangkap 2 : Accounting \\ Rangkap 3 : Kasir}

Setelah pihak leasing survey maka akan diberi konfirmasi kepada Administrasi. Pertama, jika permohonan disetujui maka Administrasi akan menerima PO (Purchase Order) dari pihak leasing melalui fax sebagai tanda permohonan kredit disetujui. Jika permohonan ditolak maka Sales Counter akan memberitahu pelanggan dan meminta untuk datang ke dealer agar dapat mengambil uang DP yang sudah disetor disertakan bukti SP dan Kwitansi DP.

Administrasi akan menyerahkan Faktur STNK/BPKB kepada Biro Jasa untuk dapat diurus proses pembuatan STNK dan BPKB. Lalu Administrasi akan meng-entry form Faktur
Penjualan dan form Surat Jalan serta mencetak FP (Faktur Penjualan) dan SJ (Surat Jalan). FP sebanyak 4 rangkap:

\author{
Rangkap 1 : Pelanggan \\ Rangkap 2 : Administrasi \\ Rangkap 3 : Sales Counter \\ Rangkap 4 : Kasir \\ SJ sebanyak 4 rangkap: \\ Rangkap 1 : Delivery \\ Rangkap 2 : Pelanggan \\ Rangkap 3 : Administrasi \\ Rangkap 4 : Kasir
}

Setelah FP dan SJ dicetak maka SJ akan diserahkan ke PDI dan FP ke Delivery. PDI setelah menerima SJ akan menyiapkan barang yang harus dikirim dengan terlebih dahulu memeriksa kelengkapan sepeda motor. Setelah lengkap PDI menyerahkan sepeda motor, beserta SJ ke Delivery. Lalu Delivery mengirimkan barang beserta SJ dan FP rangkap 1 ke pelanggan.

Pelanggan menerima barang, SJ dan FP rangkap 1 kemudian Delivery meminta pelanggan untuk menandatangani SJ. Setelah ditandatangani SJ rangkap 2 dan FP rangkap 1 diberikan kepada pelanggan. Lalu Delivery mendistribusikan SJ yang ditandatangan ke bagian masing-masing.

Setelah barang terkirim kasir langsung menagih sisa pelunasan kepada pihak leasing dengan PO dan SJ. Setelah menerima pembayaran sisa pelunasan maka kasir akan meng-entry pembayaran ke form pembayaran dan Kasir akan mencetak kwitansi sebanyak 3 rangkap:

$$
\begin{aligned}
& \text { Rangkap } 1 \text { : Pihak leasing } \\
& \text { Rangkap } 2 \text { : Accounting } \\
& \text { Rangkap } 3 \text { : Kasir }
\end{aligned}
$$

Setelah Biro Jasa selesai mengurus STNK dan BPKB kemudian akan menyerahkan STNK dan BPKB yang sudah jadi ke Sales Counter. Sales Counter kemudian akan menghubungi pelanggan untuk dapat mengambil STNK dan BPKB ke dealer.

\section{Prosedur Penerimaan Kas yang Diusulkan}

Setelah pelanggan menandatangani SP dan mengisi Faktur STNK/BPKB lalu menyerahkannya kepada Sales Counter. Pelanggan akan melakukan pembayaran tunai ke Kasir dan kasir akan mengentry pembayaran ke form pembayaran. Jika penjualan kredit, pelanggan akan melakukan pembayaran DP dan Kasir akan meng-entry pembayaran ke form pembayaran. Kasir akan 
mencetak Kwitansi untuk pembayaran tunai ataupun pembayaran DP sebanyak 3 rangkap:

Rangkap 1 : Pelanggan

Rangkap 2 : Accounting

Rangkap 3 : Kasir

Jika penjualan kredit maka pihak leasing akan membayar sisa pelunasan dan Kasir akan meng-entry pembayaran ke form pembayaran dan mencetak kwitansi sebanyak 3 rangkap:

Rangkap 1 : Pihak leasing

Rangkap 2 : Accounting

Rangkap 3 : Kasir
Setiap transaksi yang terjadi harus disimpan secara terkomputerisasi sehingga dapat diakses dengan mudah dan peng-entry-an transaksi yang sama cukup dilakukan satu kali saja. Dengan demikian, dibutuhkan sebuah database yang saling terhubung satu sama lain (terlihat dalam Gambar 4). 
Berikut ini adalah salah satu contoh diagram penjualan tunai untuk menggambarkan hubungan antara aktor dengan sistem (Gambar 5). 


\section{PENUTUP}

Simpulan yang dapat diperoleh dari penelitian ini adalah analisis dan perancangan berbasis objek akan memudahkan pembangunan sistem pendapatan. Pada penelitian ini, sistem pendapatan telah dirancang untuk diimplementasikan oleh perusahaan yang bergerak dalam bidang dealer kendaraan bermotor. Namun, sistem yang dirancang masih membutuhkan database yang terintegrasi dengan aplikasi yang digunakan. Sistem ini diharapkan dapat meningkatkan kecepatan dan ketepatan dalam pengolahan data dan menghasilkan laporan sesuai kebutuhan manajemen perusahaan.

\section{DAFTAR PUSTAKA}

Connoly, T. and C. Begg. 2002. Database System: A Practical Approach to Design, Implementation, and Management. $3^{\text {rd }}$ Edition. USA: Addison Wesley.

Fowler, M. and K. Scott. 2000. UML Distilled. $2^{\text {nd }}$ Edition. USA: Addison Wesley Longman.

Hall, James A. 2001. Accounting Information System. South Western Publishing.

Hoffer, A., Jeffrey, Prescott, B., Mary, McFadden, R. Fred. 2002. Modern Database Management. $7^{\text {th }}$ Edition. Prentice Hall.

Jason, T. Roff. 2003. UML a Beginner's Guide. California: McGraw-Hill.

Jones, F. L., Rama, D. V. 2003. Accounting Information System: A Business Process Approach. Ohio: South-Western Publishing.

McLeod, R. 2001. Sistem Informasi Manajemen Jilid 1. Edisi ke-7. Jakarta: PT Prenhallindo.

Mulyadi. 2001. Sistem Akuntansi. Jakarta: Salemba Empat.

Munk-Madsen, A., Mathiassen, L., Nielsen, P. A., Stage, J. 2000. Object Oriented Analysis and Design, $1^{\text {st }}$ Edition. Denmark: Marko Publishing.

O'Brien, James A. 2002. Introduction to Information $\quad$ System. $11^{\text {th }}$ Edition.McGraw-Hill.

Whitten, L. Jeffery, Bentley, D. Lonnie, Dittman, C. Kevin. 2004. System Analysis and Design Methods. McGraw-Hill. 